\title{
Guidance of children visiting in the adult intensive care by nurses
}

\author{
EM de Vries-van Hooff ${ }^{1 *}, C$ de Kuijer ${ }^{2}, T$ van Galen ${ }^{3}$ \\ From ESICM LIVES 2015 \\ Berlin, Germany. 3-7 October 2015
}

\section{Introduction}

At the 22 bed ICU at VU University medical center (VUmc) there was no uniform approach to the guidance offered by nurses to children visiting the adult ICU. Visitation was frequently discouraged. No educational material was available to prepare a child for a visit. The guidance of children does not form part of ICU training. Research has shown it is good to allow children on the adult ICU provided that they are well prepared and guided (Vint, 2005) [1]. These research findings together with observations during day-to-day practice were reason for further study and applying interventions for improvement. The target group is children between the ages of 4 to 12 .

\section{Methods}

A literature study was performed, followed by a survey with open and closed questions for nurses working in the adult ICU. Interventions were developed and implemented by a multidisciplinary focus group consisting of an IC nurse, a bachelor student and pedagogical colleagues.

\section{Results}

85 nurses received the survey. The response rate was $80 \%$. The survey results confirmed the observation made during day-to-day practice. $10 \%$ of the respondents indicated that a uniform approach was used by nurses to provide guidance.

The survey showed that the guidance provided was based mainly on intuition.

The focus group initiated the following interventions:

1. Protocol for the guidance of children by nurses to promote a uniform approach.

2. An informative picture book explaining what to expect while visiting the ICU, written in a language

understood by children. This book can be read to by family or a nurse or by the child itself from ages 7 and up.

3. A backpack is available for children who are in need of more information after a visit. The backpack contains materials used in the ward. This will help the children to make it palpable.

\section{Discussion}

After a short research period three interventions were implemented to improve children's guidance offered by the ICU nurses before and during a visit. In the past visits to the ICU by children were frequently discouraged, now visits are encouraged and the educational materials are leading to a more uniform approach to providing guidance. In addition to the above interventions parents are provided with an informative leaflet to help prepare a child for a visit. The picture book is part of the ICU website. In September 2015 the results of the interventions will be measured among the IC nurses. On January $30^{\text {th }}$ 2015 a national workgroup was formed: Family and patient Centered Intensive Care[2] (FCIC), with the aim of achieving national alignment on this topic.

\section{Authors' details}

${ }^{1}$ RN, VU University Medical Center, Intensive Care, Amsterdam, Netherlands. ${ }^{2}$ Holland University, Amsterdam, Netherlands. ${ }^{3} \mathrm{ICU}$ Nursing, VU University

Medical Center, Intensive Care, Amsterdam, Netherlands.

Published: 1 October 2015

\section{References}

1. Vint P: Children visiting adults in ITU. Nursing in Critical Care 2005, 10(2):64-71.

2. [http://www.opeenicliggen.nl/family-centered-intensive-care-fcic/].

doi:10.1186/2197-425X-3-S1-A724

Cite this article as: de Vries-van Hooff et al:: Guidance of children visiting in the adult intensive care by nurses. Intensive Care Medicine Experimental 2015 3(Suppl 1):A724.

\section{SpringerOpen ${ }^{\circ}$}

(c) 2015 de Vries-van Hooff et al.; This is an Open Access article distributed under the terms of the Creative Commons Attribution License (http://creativecommons.org/licenses/by/4.0), which permits unrestricted use, distribution, and reproduction in any medium, provided the original work is properly cited. 